\title{
INFLUENCE OF EMERGENT VEGETATION ON SEDIMENT YIELD AT CROSS-SHORE COASTAL ENVIRONMENTS
}

\author{
Umut Türker' ${ }^{1}$ Oral Yagci², Amin Riazi ${ }^{3}$ and Sedat Kabdasli ${ }^{4}$
}

\begin{abstract}
This study aimed to conceptually analyze the change in the magnitude of offshore sediment yield, wave energy, and offshore dislocation of sediment particles on coastal regions in the presence of coastal vegetation. This was achieved by comparing the simultaneous physical changes at coastal zones that were partly covered with vegetation while the remaining part had no vegetation. Series of experiments were conducted, and the interactions between the vegetation parameter, ratio of sediment yields, and offshore sediment dislocation distances were analyzed and determined to define the relationship between the parameters. The resultant empirical equations mostly followed a power relationship and fit the experimental data. The energy decay coefficient, reflecting the energy used in the presence of the vegetation, had strong protection ability and approached $80 \%$ energy decay as the vegetation parameter increased. The performance of natural vegetation cover was adequate, simulating a $50-80 \%$ decrease in offshore sediment yield, depending on the magnitude of the vegetation parameter.
\end{abstract}

Keywords: physical model; offshore bar; sediment yield; vegetation; wave energy decay

\section{INTRODUCTION}

Vegetation cover can increase the flow resistance, control the flow characteristics, and modify the sediment transport and deposition in natural channels and coastal areas. Vegetation plays a major and positive ecological role in ocean, estuary, and lagoon ecosystems (Boudouresque, 2004). There are considerable information regarding sediment dynamics in coastal regions in the absence of vegetation (Camenen and Larson, 2008; Grasso et al., 2009; Goda, 2006; Masselink, 2004). In the last decade, there has been a growing interest in research on the impact of vegetation on coastal sediment movements and how these movements can affect ecological balance (Gacia and Duarte, 2001; Nepf and Vivoni, 2000; Yen, 2002; Luhar et al., 2013).

The effects of vegetation on seabed morphology and on the interaction between fluid flow, sediment transport, and vegetation cover can be better understood by conducting controlled laboratory experiments. In controlled laboratory environments, $\mathrm{v}$ arious parameters that are not easily measurable under natural conditions can be measured. Kobayashi et al. (1993) proposed an analytical expression for submerged vegetation and tested the phenomenon by using experimental data from experiments conducted in a wave tank roughened with artificial vegetation elements. The effect of different vegetation species (i.e., Laminaria hyperborea) on wave propagation, wave run-up, and coastal and dune erosion rates were later studied and modeled by other researchers (Lovas and Torum, 2001; Massel et al., 1999; Noarayanan et al., 2012; Le Bouteiller and Venditti, 2014). These laboratory-based studies were designed mainly to understand the interaction between vegetation and flow resistance. In coastal studies, vegetation cover significantly decreases flow or wave energy, which results in reduced sediment motion. Usually, accretion of sediments as an offshore bar is due to the cross-shore wave attack during storms. These waves are characterized by their short periods and large wave heights. The propagation of eroded sediments in the offshore direction is generally facilitated in the presence of storm waves and continues until the wave energy is sufficient to initiate the motion of sediment particles. On the other hand, coastal vegetation is a natural protect against the initiation of sediment motion. This protection is usually afforded by wave attenuation and root stability at dune fronts.

All field, laboratory, and numerical studies indicate that coastal vegetation of a certain density can considerably reduce wave energy and protect the coast from erosion by minimizing sediment dislocation. However, further research is required to derive the general principles underlying the protective role of coastal vegetation in combating coastal erosion and sediment transport. This study investigated the effects of vegetation cover on the magnitude of offshore sediment yield (bar formation), dislocation of sediments, and attenuation of wave energy. Our findings suggested that vegetation improved coastal stability, consolidated sediments, and reduced wave energy, all of which are required for minimizing the offshore transport of coastal sediments. The most obvious reduction in offshore sediment yield was noted when the population of vegetation was maximum.

\footnotetext{
${ }^{1}$ Civil Engineering Department, Eastern Mediterranean University, Famagusta, 99450, North Cyprus.

${ }^{2}$ Civil Engineering Faculty, Istanbul Technical University, Maslak, 34469, İstanbul, Turkey.

${ }^{3}$ Civil Engineering Department, Eastern Mediterranean University, Famagusta, 99450, North Cyprus.

${ }^{4}$ Civil Engineering Faculty, Istanbul Technical University, Maslak, 34469, İstanbul, Turkey.
} 


\section{SEDIMENT TRANSPORT DEFINITION}

The wave energy transferred from the offshore leads to erosion, generating intensive sediment transport causing coastal profile changes. The sediment transport mechanism eventually desists when considerable amount of sediment grain yields at some point offshore, forming an offshore bar. Usually, accretion as a bar formation is the sediment yield trapped offshore, which is an indicator of the total sediment eroded from coastal regions. The sediment yield is due to the dislocation of sediment grains. During wave breaks, the sediments are subjected to a force that initiates their motion and maintains displacement in an offshore direction. As the energy of the approaching wave increases, the size of the disturbance on sediment grains increases and the motivation of separation between the grains and the boundary enlarges and sediment grain stability declines, all of which signify offshore incipient motion.

The incipient motion occurs when the stability of sediment particles is disturbed. Such stability can be attributed to the net imbalance of forces or force exerted on the particles. By considering a unit area of a coastal zone inclined at angle $\alpha$ to the horizontal, the forces acting on sediment grains are the weight and tangential force. The former always pulls the sediments in the downward direction and the latter maintains their offshore motion. The work done by the fluid in unit time that brings the sediment grains into motion can be determined by taking the product of tangential stress and mean speed, $v_{s}$, of sediments. Hence, the fluid power, $P_{f}$, expended per unit bed area in transporting the sediment load is given as follows (Bagnold, 1963):

$$
P_{f}=\frac{\rho_{s}-\rho}{\rho_{s}} g m \cos \alpha(\tan \beta-\tan \alpha) v_{s}
$$

where $m$ is the whole mass of the displaced sediment per unit area; $\rho_{s}$ and $\rho$ are the densities of sediment and pervading fluid, respectively; $\beta$ is the angle of repose, which is a measure of the mean angle of contact between the sediment grains; and $v_{s}$ is the mean speed. The mean speed can be defined as the ratio of the average dislocation of sediment particles to the time required for the dislocation.

$$
v_{s}=\Gamma / \delta
$$

where $\Gamma$ is the average distance displaced by sediment particles, and $\delta$ is the time interval starting with the incipient motion of sediments from foreshore to offshore, until the sediments settle. The ratio of the mass load of sediments to their density is related to the volume of sediment particles. Therefore, the energy required to dislocate sediment grains in unit time per unit area can be resolved as follows:

$$
\mathrm{E}=\left(\gamma_{s}-\gamma_{w}\right) S_{y} \cos \alpha(\tan \beta-\tan \alpha) \Gamma / \delta
$$

where $\gamma_{\mathrm{s}}$ and $\gamma_{\mathrm{w}}$ are the specific weights of sediments and fluid, respectively, and $\mathrm{S}_{\mathrm{y}}$ is the volume of sediment particles. The wave energy facilitates the dislocation of sediment particles toward the offshore to form an offshore bar. The offshore bar is the total yield of the eroded sediments characterized by its volume, and it defines the scale of erosion at the coastal zone. Therefore, the volume of sediment particles, $S_{y}$, is the optimum volume of sand contained within the bar per unit length. In the derivation of the above equations, the sea state and boundary conditions are assumed stationary over the duration of a morphological time step and the porosity of the bed material is uniform.

\section{THE WAVE ENERGY DECAY COEFFICIENT AND VEGETATION PARAMETER}

Vegetation cover is the main factor that influences the hydraulic properties of incoming wave energy. In the literature the physics and behavior of waves passing through vegetation, mainly focusing on wave attenuation due to vegetation field have been investigated (Augustin et al., 2009; Elginoz et al., 2011; Mendez and Losada, 2004; Yagci et al., 2011; Möller et al., 2014). Herein, a simple and general symbolic non-dimensional vegetation parameter is proposed that can define the magnitude of wave energy attenuation while waves propagate through the vegetation field. The non-dimensional parameter can be used to represent the geometry, density distribution, relative submergence, and flexibility of the vegetation. Vegetation increases resistance and, therefore, decreases the wave energy, which modifies sediment transport and its offshore yield.

Wave attenuation by vegetation field is mainly a function of plant characteristics such as the geometry, stem thickness, height, spatial coverage, and stiffness. Wave decay coefficient as a function of plant characteristics can reflect the differences on wave energy attenuation between the absence and 
presence of vegetation fields. This can be achieved when similar hydrodynamic conditions, including water depth, wave period, and wave height, can be maintained in both the absence and presence of vegetation fields. In such a case, the relationship between energy levels with or without vegetation field can be formulated as follows:

$$
\varepsilon=\sqrt{\frac{E_{v}}{E_{o}}}
$$

where $\varepsilon$ is the wave decay coefficient, $E_{v}$ is the energy passing through the vegetation field, and $E_{o}$ is the approaching wave energy. Normally, wave energy is defined in terms of wave height, hence, the square root of the energy ratio in Eq. (4) has been used. Moreover, the wave decay coefficient through the vegetation field can be expressed as a function of plant characteristics and wave properties.

$$
\varepsilon=f\left(\xi, \Delta s, \Delta d, \phi, H_{v}, H_{o}, T_{v}, T_{o}, \rho, g\right)
$$

where $\xi$ is the modulus of stiffness of vegetation, $\Delta \mathrm{s}$ is the distance between the stems in the flow direction, $\Delta \mathrm{d}$ is the perpendicular distance to the flow direction (Fig. 1) between each stem, $\phi$ is the diameter of each stem, and $\mathrm{H}$ and $\mathrm{T}$ are wave height and period, respectively. Since wave energy is a function of wave height, Eq. (4) represents the ratio between the incoming wave height and wave height passing through the vegetation field. The plant characteristics that influence wave energy decay are the modulus of elasticity, the mean diameter and the number of stems involved, and the spacing between two adjacent stems.

$$
\varepsilon=f(\Delta s, \Delta d, \xi, \phi)
$$

Modulus of elasticity refers to the resistance of stems standing against the impact of waves, which is an effective parameter for wave attenuation. However, in this study, all the stems were the same and had constant effects on wave attenuation. Thus, there was no need for a detailed investigation of the modulus of elasticity. Instead, the number of stems, $n$, was considered as an important parameter. Consequently, a dimensionless parameter defined in terms of the above parameters can be developed to represent the effect of vegetation cover on wave attenuation and sediment transport. The dimensionless vegetation parameter, $\lambda$ can be used to reflect the effect of vegetation field in terms of the number of stems within a predefined constant width and stem position.

$$
\lambda=f(\Delta s, \Delta d, n, \phi)
$$

By applying the Buckingham $\pi$-theorem to Eq. (7), the dimensionless vegetation parameter can be defined as:

$$
\lambda=n \frac{\phi^{2}}{\Delta s \times \Delta d}
$$

where the dimensionless vegetation parameter represents the number of stems distributed in a vegetation field defined by the number of stems per unit area. Since the number of stems per unit area is constant, increase in the number of stems signifies an increase in the length of the vegetation field. The dimensionless parameters given in Eq. (4) and Eq. (8) can be used to evaluate wave attenuation along the vegetation field on the basis of wave and plant characteristics.

\section{CROSS-SHORE SEDIMENT YIELD}

The cross-shore sediment yield in the form of an offshore bar is a ubiquitous feature along wavedominated coastal regions. It is one of the most dynamic elements of the nearshore profile and has widely been studied since it plays an important role in protecting the coastal zone from erosion (Van Houwelingen et al., 2006). The volume of sediments contained within offshore bars provides a natural barrier to force the waves to break on the bar and dissipate their energy during storms. Under those circumstances, understanding the behavior of bar formation (offshore sediment yield), as well as the contribution of the vegetation field in controlling and minimizing cross-shore sediment transport in coastal zones, is important. According to Silvester and Hsu (1997) and Türker and Kabdaşlı (2004), the dominant parameters for estimating the cross-shore sediment yield, $S_{y}$, are defined using the following parameters: 


$$
S_{y}=f\left(m, d_{50}, H, T, \rho, g, L, w, \rho_{s}\right)
$$

where $H, T$, and $L$ refer to the wave height, period, and length, respectively; $w, \rho_{\mathrm{s}}$, and $d_{50}$ are sediment fall velocity, density, and mean diameter, respectively; and $m$ is the slope of the coastal profile. As the incoming wave height increases, more energy dissipates during the wave break, motivating more sediments to join the cross-shore sediment yield. Furthermore, as the size of the sediment particles increases, more energy is required to initiate their cross-shore motion.

\section{EXPERIMENTAL INSTALLATION}

The experiments were conducted in two different rectangular flumes. The sidewalls and bottom of the flumes were made of glass and steel, respectively. Flumes with dimensions of $24 \times 1 \times 0.5 \mathrm{~m}$ and $22.5 \times 0.5 \times 0.5 \mathrm{~m}$ were used to generate irregular and periodic waves, respectively. The schematic details of area of concern and its laboratory model are shown in Fig. 1 and Fig. 2. Each flume was divided into two sections: one with vegetation and another with no vegetation. Both sections simultaneously experienced the same wave properties (wave height, period, and length). Four series of tests (A, B, C, and D) were performed. Regular waves were used in series A and B, and irregular waves were used in $\mathrm{C}$ and $\mathrm{D}$. The still water depth of regular waves was $0.33 \mathrm{~m}$, and that of irregular waves was $0.60 \mathrm{~m}$. The sediment used in the tests was non-cohesive sand with a median grain size of $0.38 \mathrm{~mm}$. The slope of the coastal zone was 1:5. Before starting each experiment, the sand bed was leveled, and the location of vegetation cover was checked to ensure identical conditions for all experiments. Timber cylinders, with an average diameter of $5 \mathrm{~mm}$, positioned at one end of the flume in tandem configuration were used in all experiments. Spacing between each stem element was $20 \mathrm{~mm}$ in the cross-stream direction and $20 \mathrm{~mm}$ in the approaching wave direction.

Stems were anchored at the roots in the sand by using timber supports to maintain stability. Number of rows of tandem configuration in the wave direction was $7,15,30$, and 45 . Twenty-eight experiments were conducted and for each experiment, the ratio between offshore sediment yield and the corresponding vegetation parameter was assessed. Table 1 list the ranges of vegetation parameter, $\lambda$; incoming wave height, $H$; wave period, $T$; volume of the sediment yield, $S_{y}$; and the average distance displaced by sediment particles, $\Gamma$, in both regular and irregular wave conditions.

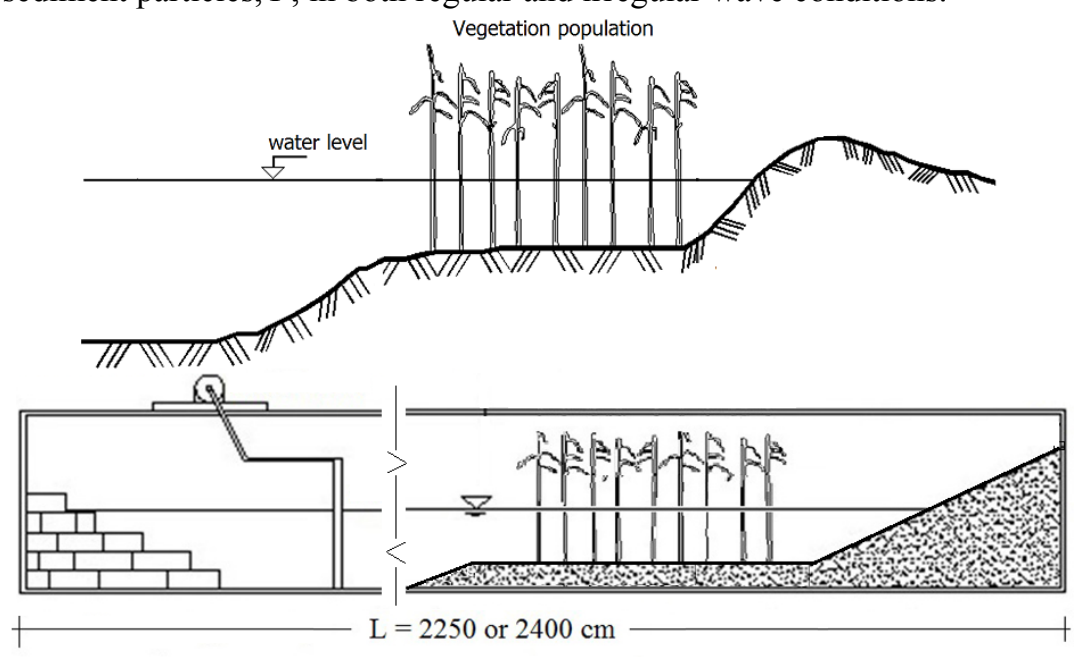

Figure $1 \mathrm{~A}$ pictorial representation of the focus area of this study (above). Experimental setup of rectangular wave flume (below). 


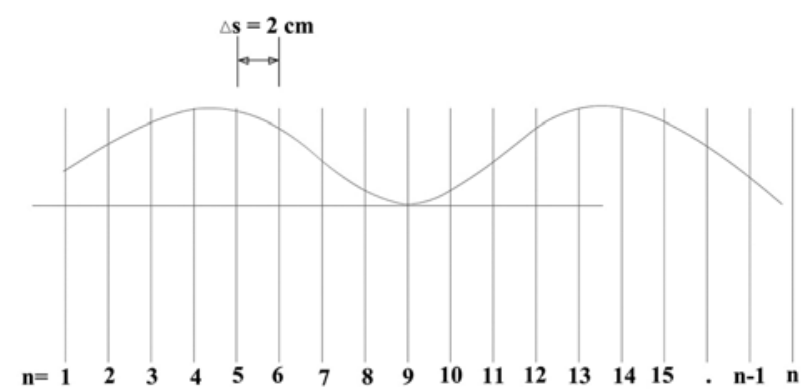

(a)

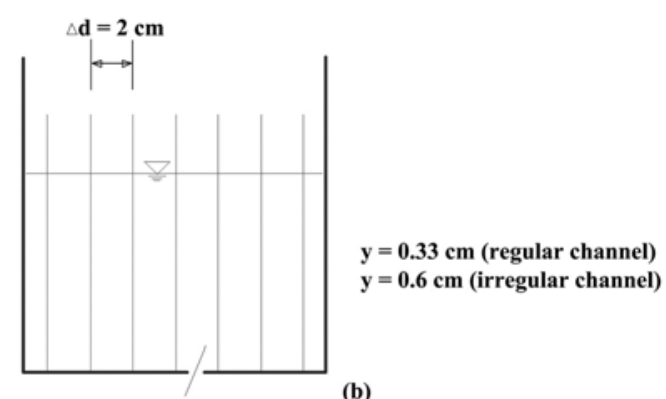

$50 \mathrm{~cm}$

Figure 2. Schematic representation of the vegetation cover in rectangular flumes. (a) wave propagation in the flow direction within the vegetation where $n$ approaches to 45; (b) cross-section of rectangular flume showing vegetation cover perpendicular to flow direction.

\begin{tabular}{|l|l|l|l|l|l|l|}
\hline \multicolumn{2}{|l|}{ Table 1. The results of regular and irregular wave flume experiments. } \\
\hline $\begin{array}{l}\text { Experiment } \\
\text { Name }\end{array}$ & Wave & $\begin{array}{l}\text { Wave } \\
\text { Teight, } \\
\mathrm{H}(\mathrm{cm})\end{array}$ & $\begin{array}{l}\text { Wave } \\
\text { Period, } \\
\mathrm{T}(\mathrm{sec})\end{array}$ & $\begin{array}{l}\text { Volume of } \\
\text { Sediment Yield, } \\
\mathrm{S}_{\mathrm{y}}\left(\mathrm{cm}^{3} / \mathrm{cm}\right)\end{array}$ & $\begin{array}{l}\text { Displacement } \\
\text { of Sediment Particles, } \\
\Gamma(\mathrm{cm})\end{array}$ & $\begin{array}{l}\text { Vegetation } \\
\text { Parameter, } \\
\lambda\end{array}$ \\
\hline V1-V4 & regular & $7.1-10.7$ & $0.75-1.15$ & $59.1-209.3$ & $36.9-50.2$ & 8,625 \\
V5-V8 & regular & $6.4-13.2$ & $0.75-0.9$ & $148.5-185.4$ & $39.7-48.7$ & 20.12 \\
V9-V12 & regular & $7.1-13.8$ & $0.63-0.79$ & $48.7-141.35$ & $21.3-32.0$ & 41.68 \\
V13-V15 & regular & $7.2-9.5$ & $0.74-0.84$ & $71.8-96.3$ & $25.4-28.2$ & 63.25 \\
V101-V104 & irregular & $7.1-10.7$ & $0.95-1.13$ & $137.1-395.5$ & $50.1-82.2$ & 8,625 \\
V105-V108 & irregular & $6.4-13.1$ & $0.84-1.09$ & $94.0-433.6$ & $41.9-63.6$ & 20.12 \\
V109-V112 & irregular & $7.1-13.1$ & $0.87-1.15$ & $284.0-78.5$ & $30.7-45.5$ & 41.68 \\
V113-V114 & irregular & $8.5-9.5$ & $0.88-0.99$ & $97.3-148.4$ & $56.1-59.4$ & 63.25 \\
WV1-WV4 & regular & $7.1-10.7$ & $0.75-1.15$ & $87.6-291.9$ & $45.3-59.8$ & - \\
WV5-WV8 & regular & $6.4-13.2$ & $0.75-0.9$ & $254.9-322.3$ & $50.4-64.5$ & - \\
WV9-WV12 & regular & $7.1-13.8$ & $0.63-0.79$ & $187.1-299.4$ & $40.2-57.8$ & - \\
WV13-WV15 & regular & $7.2-9.5$ & $0.74-0.84$ & $233.2-238.3$ & $44.2-55.7$ & - \\
WV101-WV104 & irregular & $7.1-10.7$ & $0.95-1.13$ & $154.9-422.5$ & $50.6-85.8$ & - \\
WV105-WV108 & irregular & $6.4-13.1$ & $0.84-1.09$ & $170.4-507.3$ & $52.3-91.4$ & - \\
WV109-WV112 & irregular & $7.1-13.1$ & $0.87-1.15$ & $143.5-210.6$ & $52.3-99.6$ & - \\
WV113-WV114 & irregular & $8.5-9.5$ & $0.88-0.99$ & $157.8-308.3$ & $65.8-77.8$ & - \\
\hline
\end{tabular}

\section{RESULTS AND DISCUSSION}

In all the experiments, the position of sediment yield was further offshore in non-vegetated profiles than in vegetated ones. This indicated the dominant effect of wave energy on offshore-onshore sediment dislocation behavior. Offshore sediment yield formed closer to the original shoreline as the length of the vegetation field increased. Ripples behind the offshore bars were formed in most of the irregular wave flume tests (Tests C and D). The ripples were plotted in profile drawings and were determined to be important factors in defining the suspension of sediment grains. The ripples indicated that the energy of the waves was large enough to create chaotic turbulence fields at the beach slope (Chang and Hanes, 2004). In test series A and B, ripples did not affect offshore sediment yield because they were dampened by the incoming periodic waves, leaving a relatively flat bed.

In the experimental series in which the vegetation parameter was high $(\lambda=63.25)$, less erosion observed and corollary to this the magnitude of offshore sediment yield minimized. This indicated that the vegetation parameter was sufficient to dissipate the energy of the waves approaching the coastal zone, and that the vegetal parameter has significant effects on wave attenuation and energy dissipation. Therefore, the ratio between the offshore sediment yields with and without vegetation was always between zero and one. Fig. 3 and Fig. 4 are divided into two equal parts through the $y=x$ line (i.e., the z-line). The z-line represents the boundary of offshore sediment yield at which the yields in nonvegetated and vegetated coastal profiles are equal. Since the hydrodynamic characteristics of each experiment for vegetated and non-vegetated conditions were the same, the plots were always below the z-line, indicating the inevitable energy dissipation through the vegetation field. Note that the p-line, the lower limit of the relationship of the offshore sediment yield for with and without vegetation conditions, lies below the z-line. For proper classification, the data below the p-line indicate high protection, and those above the p-line indicate moderate protection. 


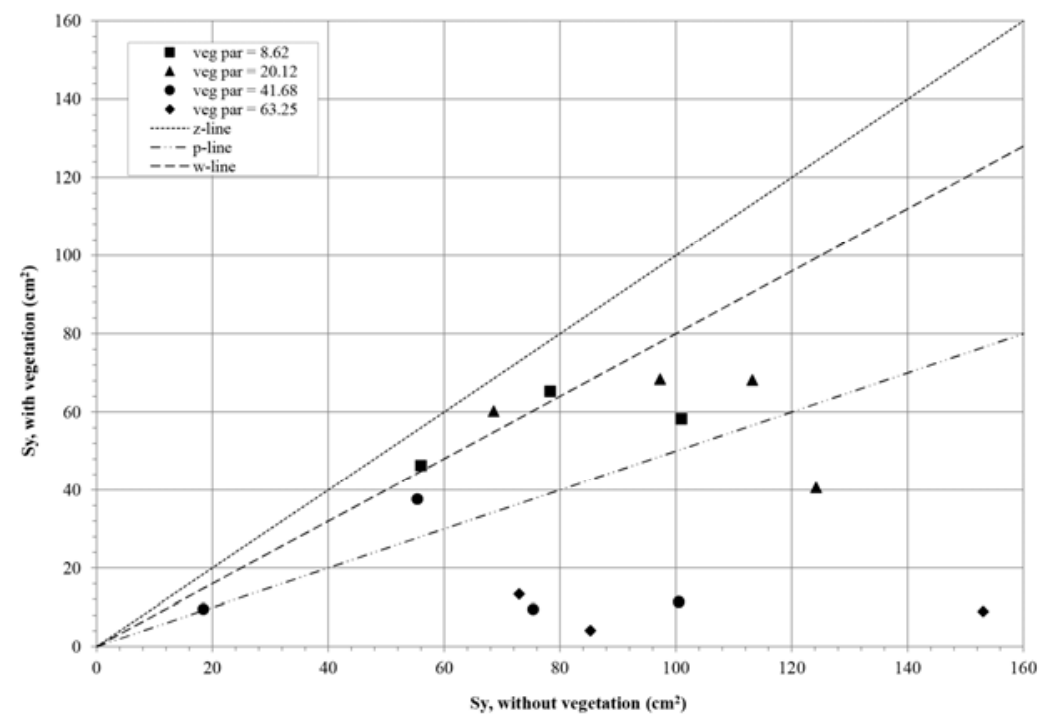

Figure 3 The relationship between offshore sediment yield in experiments with and without vegetation under regular wave conditions, indicating the inevitable decrease in the sediment transport capacity in the presence of vegetation.

The data above the w-line and below the $\mathrm{z}$-line indicate poor protection. The classification of experimental results for regular and irregular waves is summarized in Table 2. In Table 2, the coding for experiments is indicated by numbers representing the sediment yield ratio between experiments with vegetation and without vegetation (i.e., 3 represents the ratio between results of experiments V3 and WV3, and 112 represents ratio between V112 and WV112). The p-line represents the boundary for $50 \%$ reduction in offshore sediment yield, and the z-line represents a $20 \%$ reduction. The classification shows that, as the magnitude of vegetation parameter increases, the ratio of sediment yields increases.

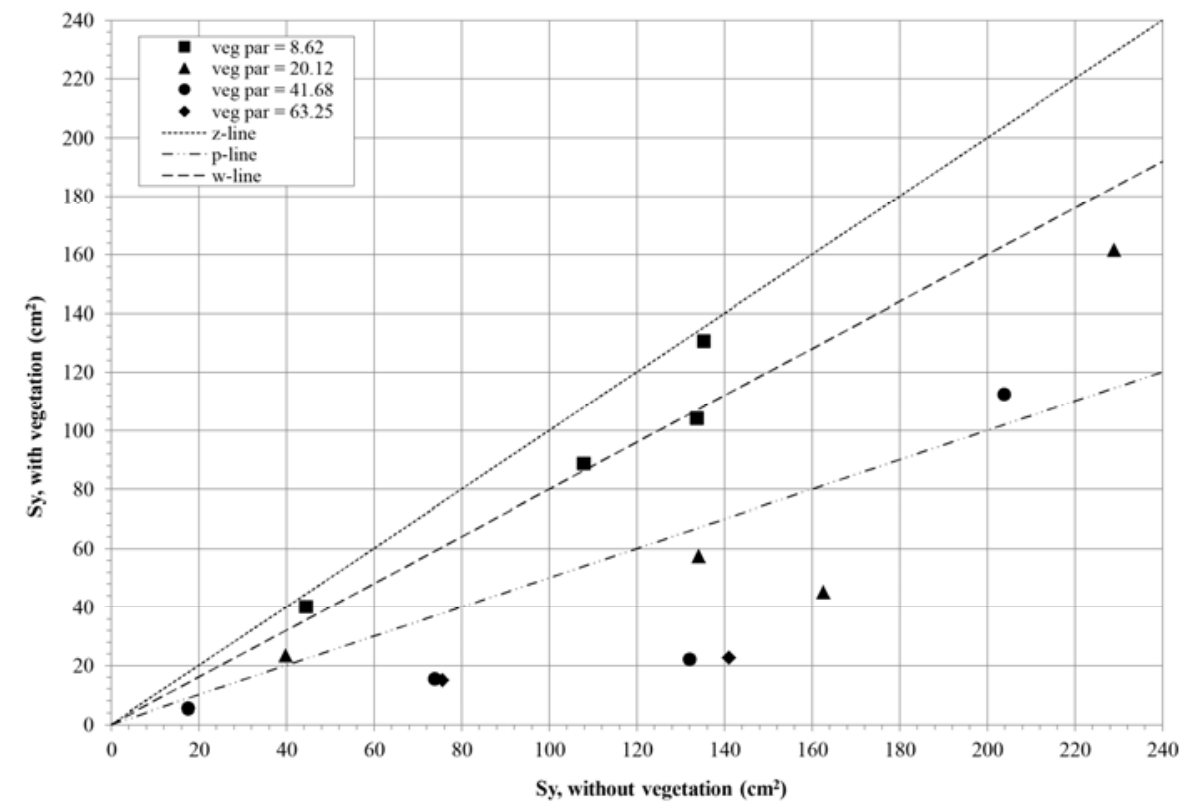

Figure 4 The relationship between offshore sediment yield in experiments with and without vegetation under irregular wave conditions, indicating the inevitable decrease in the sediment transport capacity in the presence of vegetation 


\begin{tabular}{|c|c|c|c|c|c|c|}
\hline \multirow[t]{2}{*}{$\lambda$} & \multicolumn{3}{|c|}{ Exp. Codes A and B } & \multicolumn{3}{|c|}{ Exp. Codes C and D } \\
\hline & poor & moderat & good & poor & moderate & good \\
\hline 8.63 & $\begin{array}{l}2 \\
3\end{array}$ & 1 & & $\begin{array}{l}101 \\
102 \\
104\end{array}$ & 103 & \\
\hline 20.13 & $\begin{array}{l}5 \\
7\end{array}$ & 4 & 6 & & $\begin{array}{l}105 \\
108\end{array}$ & $\begin{array}{l}106 \\
107\end{array}$ \\
\hline 41.68 & & $\begin{array}{c}8 \\
11\end{array}$ & $\begin{array}{c}9 \\
10\end{array}$ & & 112 & $\begin{array}{l}109 \\
110 \\
111\end{array}$ \\
\hline 63.25 & & & $\begin{array}{l}12 \\
13 \\
14\end{array}$ & & & $\begin{array}{l}113 \\
114\end{array}$ \\
\hline
\end{tabular}

\section{Classification of Offshore Sediment Yield}

Thus far, emphasis has been placed on the effects of vegetation cover on the cross-shore sediment yield. As the cross-shore representative sediment population increases, the number of experiments in the "good" status increase. This aspect was investigated by analyzing the trend between the vegetation parameter and the ratios of sediment yields of simultaneous tests. The dimensionless plot in Fig. 5 shows the variation in the ratios of cross-shore sediment yield with vegetation parameter. A power relationship was noted between the two dimensionless parameters, followed by a good trend for both regular and irregular wave tests. The coefficient of determination for regular and irregular wave tests was 0.55 and 0.75 , respectively.

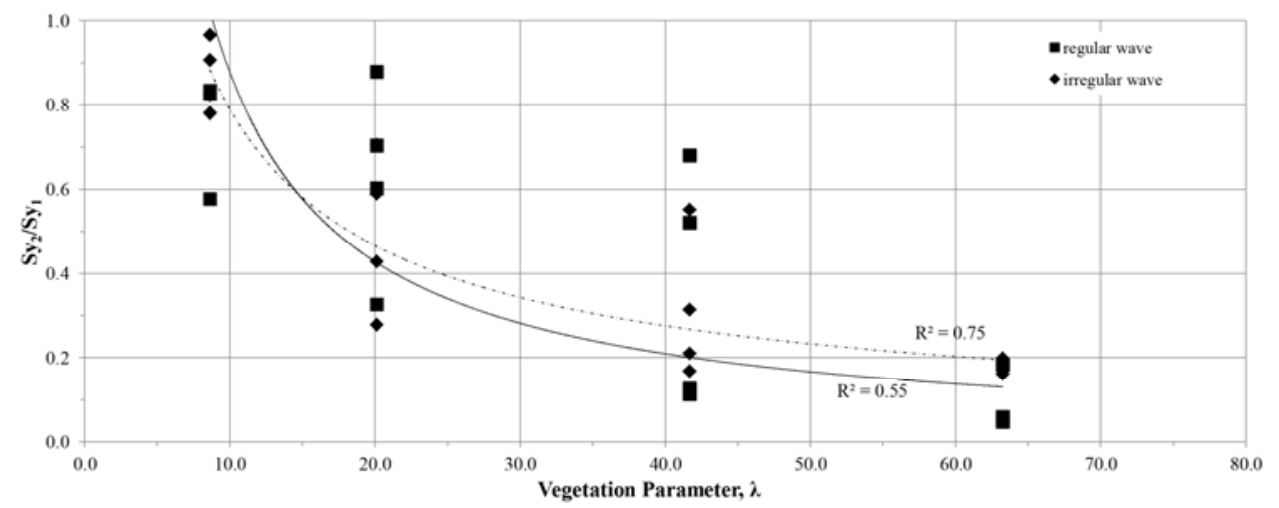

Figure 5 The sediment yield ratio approaches to zero while the vegetation parameter goes to infinity, the effect of vegetation disappears $\left(\mathrm{Sy}_{1}=\mathrm{Sy}_{2}\right)$, as the vegetation parameter gets smaller.

In the case of no vegetation, the ratio of sediment yields of non-vegetated and vegetated experiments should be equal to one. Therefore, when the vegetation parameter is zero, the ratio between the sediment yields will approach one. On the other hand, as the vegetation parameter becomes larger, the ratio of sediment yields will approach zero. The resultant regression equations for regular and irregular waves are Eq. (10) and Eq. (11), respectively, as follows:

$$
\begin{aligned}
& \frac{S_{y 2}}{S_{y 1}}=9.15 \lambda^{-1.03} \\
& \frac{S_{y 2}}{S_{y 1}}=4.52 \lambda^{-0.76}
\end{aligned}
$$

in which $\mathrm{Sy}_{1}$ is the sediment yield in experiments without vegetation, and $\mathrm{Sy}_{2}$ is the sediment yield in experiments with vegetation. 


\section{Average Displacement for Offshore Sediment Yields}

The length of sediment displacement in the onshore-offshore direction depends on the magnitude of energy dissipation per unit volume necessary to move sediments from onshore to offshore. During the tests in both regular and irregular wave flumes, the cross-shore sediment yield varied in the vegetated and non-vegetated experiments, while the hydrodynamic parameters remained constant. However, for the majority of tests, as the approaching wave height increased, the offshore displacement of sediment particles increased, resulting in the formation of bars at deeper depths with bigger volumes. Therefore, the relationship between offshore sediment yield, the distances covered by eroded sediments and the effect of vegetation parameter needs to be evaluated in order to better understand the interaction between these parameters. To do so, the sediment displacement distance, $\Gamma$, is defined as the difference between the center of gravity of offshore sediment yield and the center of erosion at the foreshore. The experimental results depicted that the sediment dislocation distance, vegetation parameter and the offshore sediment yield follow a power relationship that can be linked to the incoming waves. Therefore, through genetic algorithm the power relationship is proposed in the form of

$$
\frac{S_{y 2}}{S_{y 1}}=a_{1}\left[\lambda \frac{\Gamma_{2}}{\Gamma_{1}}\right]^{a_{2}}
$$

The proposed equation is optimized through genetic algorithm (Riazi and Turker, 2017) for the evaluation of constants $a_{1}$ and $a_{2}$. The analysis showed that the vegetation parameter is inversely proportional to the offshore sediment yield. However, the change in the sediment dislocation ratio of vegetated and non-vegetated tests with respect to changes in sediment yield ratio was small when compared with the vegetation parameter. Therefore, the optimized final empirical relation that defines the ratio of offshore sediment yield in terms of vegetation parameter and sediment dislocation ratio for regular waves is well defined with the constants $a_{1}$ and $a_{2}$ as 8.65 and -1.00 , respectively. The root mean square error of the derived relationship is between the dimensionless parameters is 0.38 . On the other hand, for irregular waves the constants $a_{1}$ and $a_{2}$ are optimized with $\mathrm{a}_{1}=4.5$ and $a_{2}=-0.74$ with root mean square error of 0.18 . The plot of the experimental data in the case of regular and irregular waves is given in Fig. 6.

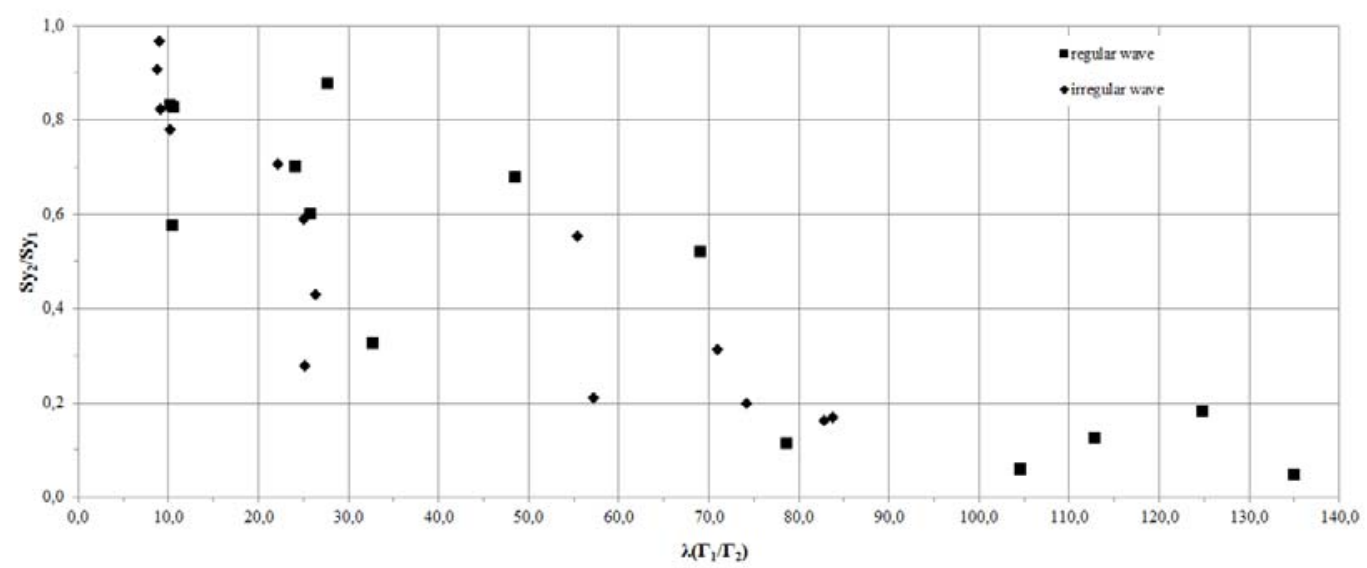

Figure 6 The sediment yield ratio depends on the product of wave parameter and sediment displacement ratio, following a power relationship.

This new graphical representation complements both sediment behavior and vegetation parameter and enlarges the applicability of defined offshore sediment yield magnitudes for various vegetation field patterns.

\section{Wave Energy Decay}

The results showed that, as the vegetation parameter increases, the wave energy necessary to transport sediments decreases. Under the effect of waves (without vegetation), the energy required to displace sediment particles in coastal regions was given in Eq. (3). However, the presence of vegetation at coastal zones diminishes the energy of the waves. Thus, in order to reflect the effect of 
energy decay at coastal regions, a reduction coefficient should be added to the energy equation given in Eq. (3):

$$
\mathrm{E}=\varepsilon\left(\gamma_{s}-\gamma_{w}\right) S_{y 2} \cos \alpha(\tan \beta-\tan \alpha) \Gamma / \delta
$$

The value of reduction coefficient, $\varepsilon$, previously defined as the wave decay coefficient, can be deduced by taking into account the difference between Eq. (3) and (13) and substituting the result into Eq. (3). This gives the percentage of energy loss that was required to initiate the motion of sediment particles to generate offshore sediment yield:

$$
\varepsilon=\frac{S_{y 1} \Gamma_{1} / \delta-S_{y 2} \Gamma_{2} / \delta}{S_{y 1} \Gamma_{1} / \delta}
$$

which can be simplified as follows:

$$
\varepsilon=1-\left[\frac{S_{y 2}}{S_{y 1}}\right]\left[\frac{\Gamma_{2}}{\Gamma_{1}}\right]
$$

Two important results are obtained from the experiments for both regular and irregular wave flumes. First, when the vegetation parameter was between 8.63 and 20.13 , the energy decay was generally around $20-60 \%$. Second, when the vegetation parameter was 41.8 or higher, the energy decay coefficient increased to $80 \%$ and more (Fig. 7).

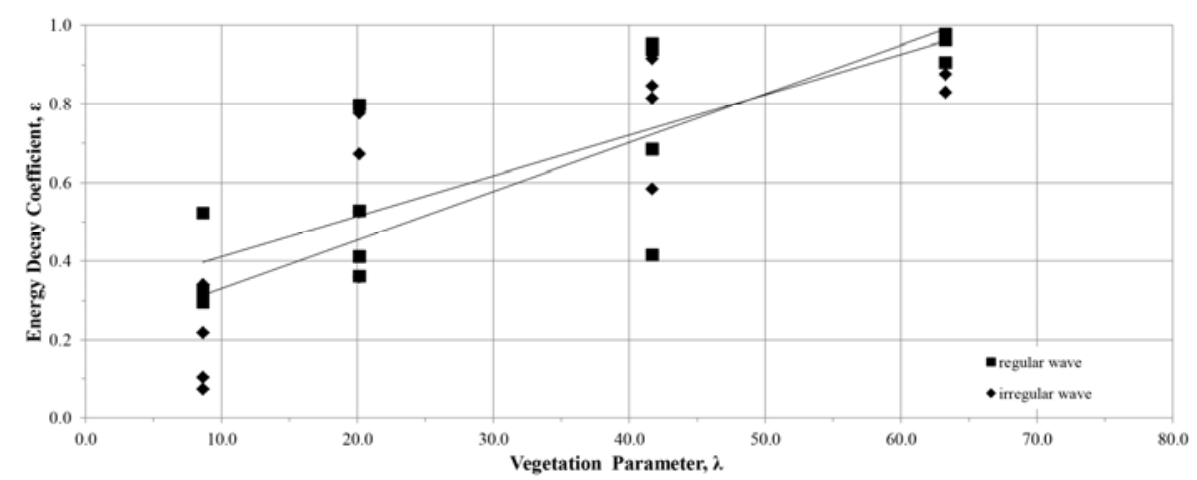

Figure 7 The energy decay coefficient is directly proportional with vegetation parameter, increasing wave attenuation as the vegetation parameter increases.

\section{CONCLUSION}

In this study, the effectiveness of vegetation with different stem populations in reducing the offshore sediment yield, displacement distance of sediment particles, and attenuation of wave energy under laboratory conditions was investigated in detail. Experiments were conducted simultaneously in the absence and presence of vegetation at coastal environments. The ratio of sediment yield of vegetated and non-vegetated experiments followed a power relationship, indicating that offshore sediment yield approaches zero as the vegetation parameter increases. The offshore displacement distance of sediments also decreased as the vegetation parameter increased. While computing the wave energy decay coefficient, both the sediment yield ratio and average sediment displacement ratio were found to play significant roles.

The investigations on model vegetation with cylindrical stems led to the formulation of parameters valid for coastal behavior under regular and irregular wave climates. The offshore sediment yield after the dislocation of sediments is best expressed in terms of the vegetation parameter and the dislocation length of the sediment particles. An empirical formula for the energy reduction coefficient at coastal zones was developed. The formula provided the basis for calculating percentage of wave energy attenuation in the presence of vegetation. The effect of flexibility of the model vegetation was not considered, whereas the length of the vegetation field was the main factor for the construction of the model. Future studies will search the effect of vegetation flexibility on wave energy attenuation and offshore sediment yield at coastal regions. 


\section{REFERENCES}

Augustin, L.N. Irish, J.L., and Lynett, P., 2009. Laboratory and numerical studies of wave damping by emergent and near-emergent wetland vegetation. Coastal Engineering, 56(3), 332-340.

Bagnold, R.A., 1963. Beach and nearshore processes part I: mechanics of marine sedimentation. In: Hill, M.N. (ed.), The Sea: Ideas and Observations, vol. 3. New York: Interscience, pp. 507-528.

Boudouresque, C.F., 2004. Marine biodiversity in the Mediterranean: status of species, populations and communities. Scientific Reports of Port-Cros National Park, 20, 97-146.

Camenen, B. and Larson, M., 2008. A general formula for noncohesive suspended sediment transport. Journal of Coastal Research, 24(3), 615-627.

Chang, Y.S. and Hanes, D.M., 2004. Suspended sediment and hydrodynamics above mildly sloped long wave ripples. Journal of Geophysical Research, 109(C07002), 1-16.

Elginoz, N., Kabdasli, M.S., and Tanik, A., 2011. Effects of Posidonia oceanica seagrass meadows on storm waves. In: Furmanczyk, K.; Giza, A., and Terefenko, P. (eds.), Proceedings, 11th International Coastal Symposium, Journal of Coastal Research, Special Issue No. 64, pp. 373-377.

Gacia, E. and Duarte, C.M., 2001. Sediment retention by a Mediterranean Posidonia oceanica meadow: the balance between deposition and resuspension. Estuarine, Coastal and Shelf Science, 52(4), 505-514.

Goda, Y., 2006. Examination of the influence of several factors on longshore current computation with random waves. Coastal Engineering, 53(2-3), 157-170.

Grasso, F. Michallet, H.; Ceratain, R., and Barthelemy, E., 2009. Experimental simulation of sandbar dynamics. In: Pereira, C.S. (ed.), Proceedings, 10th International Coastal Symposium, Journal of Coastal Research, Special Issue No. 56, pp. 54-58.

Kobayashi, N. Raichlen, A.W., and Asano, T., 1993. Wave attenuation by vegetation. Journal of Waterway, Port, Coastal and Ocean Engineering, 199(1), 30-48.

Le Bouteiller, C., and Venditti, J. G., 2014. Vegetation-driven morphodynamic adjustments of a sand bed. Geophysical Research Letters, 41(11), 3876-3883.

Lovas, S.M. and Torum, A., 2001. Effect of the kelp Laminaria hyperborea upon sand dune erosion and water particle velocities. Coastal Engineering, 44(1), 37-63.

Luhar, M., Infantes, E., Orfila, A., Terrados, J., Nepf, H. M., 2013. Field observations of wave induced streaming through a submerged seagrass (Posidonia oceanica) meadow. Journal of Geophysical Research, Oceans, 118(4), 1955-1968.

Massel, S.R. Furukawa, K., and Brinkman, R.M., 1999. Surface wave propagation in mangrove forests. Fluid Dynamics Research, 24(4), 219-249.

Masselink, G., 2004. Formation and evolution of multiple intertidal bars on macrotidal beaches: application of a morphodynamic model. Coastal Engineering, 51(8), 713-730.

Mendez, F.J. and Losada, I.J., 2004. An empirical model to estimate the propagation of random breaking and nonbreaking waves over vegetation fields. Coastal Engineering, 51(2), 103-118.

Möller, I., Kudella, M., Rupprecht, F., Spencer, T., Paul, M., van Wesenbeeck, B.K., Wolters, G., Jensen, K., Bouma, T.J., Miranda-Lange, M. Schimmels, S., 2014. Wave attenuation over coastal salt marshes under storm surge conditions. Nature Geoscience, 7(10), 727-731.

Nepf, H.M. and Vivoni, E.R., 2000. Flow structure in depth-limited, vegetated flow. Journal of Geophysical Research, 105(C12), 28547-28557.

Noarayanan, L. Mural1, K., and Sundar, V., 2012. Role of vegetation on beach run-up due to regular and cnoidal waves. Journal of Coastal Research, 28(1A), 123-130.

Riazi, A. and Turker, U., 2017. A Genetic Algorithm based search space splitting pattern and its application in hydraulic and coastal engineering problems. Journal of Neural Computing \& Applications. Accepted for publication.

Silvester, R., and Hsu, J.R.C., 1997. Coastal Stabilization. In: Liu, F. and Philip, L., (eds.), Advance Series on Ocean Engineering, Vol. 14. Singapore: World Scientific Publication, pp. 1-560.

Türker, U. and Kabdasli, M.S., 2004. Average sediment dislocation analysis for barred profiles. Ocean Engineering, 31(14), 1741-1756.

Van Houwelingen, S. Masselink, G., and Bullard J., 2006. Characteristics and dynamics of multiple intertidal bars, north Lincolnshire, England. Earth Surface Processes and Landforms 31(4), 428-443.

Yagci, O. Türker, U., and Kabdasli, M.S., 2011. Wave Damping and Retardence by Emergent Vegetation. In: Gökçekuş, H.; Türker, U., and LaMoreaux, J.W. (eds.), Survival and Sustainability, Environmental Concerns in the 21 $1^{\text {th }}$ Century. New York: Springer, pp. 1313-1320. 
Yen, B.C., 2002. Open channel flow resistance. Journal of Hydraulic Engineering, 128(1), 20-39. 